\title{
Design of an Analytical Model for Iranian Taekwondo Elites' Awareness of the Components of a Personal Brand Image
}

\author{
${ }^{1}$ Mohammad Keshtidar ${ }^{*}$, ${ }^{1}$ Kianoosh Shajie, ${ }^{1}$ Reza Heydari, ${ }^{1}$ Ali Ebrahimian Besharat \\ ${ }^{1}$ Department of Sport Management, Faculty of Sport Sciences, Ferdowsi University of Mashhad, Mashhad, Iran.
}

Submitted 14 August 2019; Accepted in final form 28 November 2019.

\begin{abstract}
Background. Today, management and development of sports brands are not only limited to sports goods, teams and leagues, but also recognized by professional and elite athletes. Objectives. So, the purpose of the present study is to analyze awareness of the components of personal brand image of male and female national team athletes and Taekwondo elite players of Iran. Methods. This study is applied and descriptive-analytical in terms of the purpose, and survey in terms of methodology. The statistical population of this study included all Iranian elite male players with a history of attending national teams. The sample size was considered as population by census and finally 150 persons formed the final sample of the study. The standard questionnaire of personal brand image of Safar et al. (2016) was used for data collection. The validity of the tool was confirmed by sport management experts and its reliability was confirmed by Cronbach's alpha of 0.87. Results. The descriptive and inferential statistics (second-order factor analysis) at the significant level of 0.05 were used to analyze the data. The results showed that among the factors that constitute the brand image, skill and style of competition had the most influence. The results also showed that the knowledge of Taekwondo elite about the components of personal brand image is at a desired level. Conclusion. According to the results, careful consideration and understanding of moral factors, skills and consulting with sports marketing and branding specialists are among the cases suggested for forming and developing a desired personal brand image for Taekwondo national and elite players.
\end{abstract}

\section{KEYWORDS: Brand, Personal Brand Image, Taekwondo, Skill, Competition Style.}

\section{INTRODUCTION}

Currently, professional sports and the sports industry are a big business, professional sports make sense with the support of sponsorship, media, athletes and spectators. As professional sports also combine several skills and businesses to form new businesses has a different structure that is expanding day by day, while professional athletes are among the key elements of professional sports businesses. Hence, the concept of sports celebrities in the sports industry has been important and taken into consideration by various sectors of the sports industry (1).
Throughout history, individuals have always sought to register symbols and place symbols and traces of themselves. Today, a brand is considered as a symbol of the identity of products and even of human beings, and the importance of the brand in forming business-related communications and trends is undeniable (2). One of the key concepts in many jobs is a brand. So that brand management is at the center of demand and a brand name takes on a tangible role. The brands can introduce a sporting goods or service with a range of these products and services. A brand is a phenomenon that affects customers and creates positive thinking

*. Corresponding Author:

Mohammad Kashtidar, Associate Professor

E-mail: keshtidar@um.ac.ir 
by adding value to a product (3). Also, given that a brand also acts as an information source, it can also serve as a tool to create a mismatch and simplify the customer decision-making process through differentiation. Therefore, today a brand is recognized as one of the most important determinants of the consumer choice in the field of services and one of the most valuable assets of any company (4). A brand is the most valuable asset for any company. A strong brand reduces its vulnerability to competitors (5). A brand is not only a product and organization monopoly and individuals can have their own brand (2). A personal brand was first used in a paper by Peters (1997). He pointed out that senior managers are more focused on products and services, while the most influential part of a market are employees and managers. He emphasized a personal brand through skills development, behavior change, and differentiation. In addition, this process is also defined as the provision of an asset that belongs to a specific person which encompasses body image, coverage, physical appearance, and knowledge backgrounds, but a personal brand is not limited to these cases and will lead to a unique, memorable and ideal feeling in the brand owner (6).

Research on a personal brand is a popular topic for academics and researchers in the field of management (7). Carter (2010) defined a personal brand as a brand, a set of individuals' perceptions of a particular person and what differs in one person from others in his personality, fame, and character. He stated that athlete's life story, values, charisma, credibility, acceptance, and success all influence the athlete's position in the audience's mind (8). Rampersad and Hubert (2008) believed that a personal brand is more than the power of influencing sales and marketing in a competitive setting. They believed that in a personal brand the effect of communication and the creation of relationships based on collaboration and positive thinking is important (9). Branding is very important in sports, which has a great effect on individuals' life and creates certain values related to fair play, a sense of cooperation, a desire to do physical activity and respect for other athletes. These relationships establish a collective bond between individuals of common interest and are one of the growing areas of business that provide many opportunities for development and prosperity (10) and a personal brand reflects objectives, differentiation, feelings, traits, habits and values of a person that are based on the same basic concepts and principles of product and company development and their main objective is communication (9).

A brand image is the perception of customers about a brand that reflects the mental associations accumulated in their memory. An athlete's brand image is defined as describing the viewers and fans' awareness of the athlete's brand and its association (11). According to Schweers and Dittel (2015), an athlete's brand image dimensions include athletic performance, attractiveness and off-field performance by influencing the image of the athlete's brand and its differentiation, it increases brand equity and finally leads to more sales of the athlete's brand (12). Talking about athletes' personal brand image requires knowledge and understanding of the basic concepts and theories of classical branding (13). The researchers such as Arai, Jae Ko and Kaplanidou (2013), and Arai, Jae, Ko and Ross (2014) based on Structural Equation Modeling obtained a reasonable fit between the data of the conceptual model and the scale description of the athlete's brand image. An athlete's brand image is defined here as a description of the customer's awareness of the athlete's brand and its associated features. The conceptual model proposed by Arai et al. (2013) as well as the tested athletic brand model proposed by Arai et al. (2014) have three primary dimensions: sport performance, attractive appearance, and marketable lifestyle. An athlete as an athletic figure and marker should appear excellent in his sport, so the primary feature of the athlete's brand should be the performance of the athlete. The performance of an athlete is his performance related features, including four sub-scales of rivalry, sport expertise, competitive style and chivalry. Sports performance is considered a product-related feature that is the primary role of athletes to improve their sport performance and develop their brand positioning on the basis of their continued success. On the other hand, other features that are not related to sport performance are considered as non-product related features (physical attractiveness and lifestyle); physical attractiveness as a "trademark" of the product brand is a major concern of most branding activities. It consists of three sub dimensions: physical attractiveness, symbolic feature, and physical fit. The physical attractiveness is the primary element of a sports face image $(11,14)$.

The significance of this study is justified by the development of team loyalty through its 
identification with elite athletes. The elite athletes are athletes who have participated in important national and international sport competitions and tournaments in the form of different sports teams (15). Similarly, Kucharska and Thomas (2017) in their study showed that today a personal brand is more important for individuals so that the use of a valuable personal brand in social media affects the level of the user's loyalty (16).

The literature review shows the significance of this research. In the national research section, a study by Saffar et al. (2016) has the most similarity with the present study. In this study entitled "development of professional athletes' personal brand image model, he showed that both internal and external factors had a significant relationship with athletes' brand image. In addition, it was found that the factor of athletic competition style and fair behavior played the most and least role in the brand image of athletes with factor loadings of 0.91 and 0.52 , respectively (17). In another study by Mahmoudian et al. (2017) the results showed that dimensions of athlete brand image (sport performance, attractive appearance, and marketable lifestyle) had a positive and significant effect on fan loyalty. Among these dimensions, a marketable lifestyle had the most effect on fan loyalty. This dimension reflects the features, activities and performance of off-field athletes. Athletes can therefore effectively manage their brand by doing activities such as enhancing a relationship with fans, appreciation, engaging in social, cultural and charitable activities, high public relations, and etc. to enjoy its associations, including the fan loyalty (12). Also, a study by Hasani et al. (2018) showed that athlete's brand image has significant effect on confirmation and identification. Identification as an intermediary has a significant effect on the athlete's brand image and confirmation. This intermediary role for sports products was more effective than non-sports products. This finding emphasizes the appropriateness of the confirmer-audience and the confirmer-product (18). In the international research section, Hermansen (2010) also examined the factors influencing the formation of athletes' personal brand image. These factors included athletic outcomes, athlete appearance and life story. In another study, Zhao and Sung Lee (2010) studied the value of personal sports brands in China and concluded that to improve conditions, different models were adapted to each athlete's condition to develop brand performance and management. Their studies showed that according to the levels of athletes, the appropriate target market should be considered. They also found that various factors, such as job stability and the team in which the athlete is a member, had an effect on the athletes' personal brand. The position of sports heroes has a major effect on their brand image, but at the same time, the performance of the athlete alone can act as a risk factor (15). Sassenberg et al. (2012) presented a conceptual model of brand image of sports celebrities and stated that sport skill levels, validity, reliability, attractiveness and personality traits are influential factors on sport celebrity brand image. Also, brand image of sports celebrities can be an effective factor on marketing relationships (19). In another study, Akiko and Yong (2013) presented a conceptual model of athlete brand image seeking to evaluate the relationship between 3 factors of athlete's personal brand and personal brand image in individual athletes. The results showed that lifestyle had the highest share in the general concept of "athlete's personal brand image", athletic performance was the second most important factor in athlete's personal brand image, and apparent attractiveness is the third factor in personal brand image presentation (20). Green (2016) conducted a study on the effect of social responsibility on the development of a personal sports brand on rugby athletes in the United Kingdom. The results showed that the tendency for the athlete's personal brand based on mental models included personality judgments, accountability, follow-up, confirmation, adaptation, and support for the community problems (21). Also, Johnson (2017) in his study entitled "teaching students how to personalize their branding showed that using social media such as Instagram, YouTube, LinkedIn, websites and blogs can affect personal branding transfer of students (22).

In recent years, many famous athletes have turned to building their own brands because of their personal branding, and ability to create and maintain a market for their customers and fans, because a good athlete's brand affects companies that are seeking confirmation. In addition, athletes are considered as fragile products due to the unexpected injuries and loss in their sport performance. Because of the high risk that athletes have to ensure their fans' loyalty when their 
performance slips, for them, gaining stability is a critical problem for them (23). Considering the effective factors for personal branding as well as identifying and analyzing the effective factors on desired formation, personal brand of athletes is very important. Famous athletes, though not necessarily clubs and sports teams, play an important role in forming the community's relationship with sport in a variety of economic, cultural, and social dimensions. Given that many studies have been conducted on brand management in sports teams, but few studies have examined the importance of athletes' personal brand, and most studies have focused on personal management of athletes as a brand confirmation rather than their own brand. For this reason, for paying attention to the personal brand of professional athletes is very important. On the one hand, there is a mentality that athletes of popular disciplines like football, basketball and etc. have the ability to personalize brand, which is not the right idea. Because each country has a history in one or more specific sports that helps individuals in a particular sport become more popular and famous than football players or others. Taekwondo is one of Iran's most popular and medalist Olympic disciplines and sees personalities like Hadi Saei as a popular personal brand. Therefore, one can conceive of personal discipline for this field in Iran and seek to establish personal branding. In general, according to the above the purpose of this study was to investigate the analytical model of Iranian Taekwondo elite players' awareness of components of personal brand image.

\section{MATERIALS AND METHODS}

The present study was an applied descriptiveanalytical one in terms of purpose and survey in terms of method. The data were collected using a personal brand image questionnaire developed by Saffar et al. (2014). The tool measures the factors influencing personal brand image on 11 subscales of fair behavior (5 items), skill (5 items), competition style (6 items), success (5 items), attractiveness (6 items), life story (4 items) ), reliability (5 items), communication (5 items), social responsibility (4 items), psychological commitment (8 items), and finally loyalty (4 items). In addition, a 7-point Likert scale (1=strongly disagree to $7=$ strongly agree) was used to quantify the data. The face and content validity of the tool was evaluated by 10 specialists and experts in sport management as well as its reliability in a pilot study conducted on 10 Iranian Taekwondo players with Cronbach's alpha of 0.87 .
The statistical population of this study consisted of all Iranian Taekwondo elite players with national and international background who were selected randomly, conveniencely and purposefully due to the nature of the research. Finally, 150 elite male taekwondo players were selected as the final sample of the study. The descriptive statistics (mean, standard deviation, and etc.) and inferential statistics (structural equation model (second order), Spearman correlation test, and single sample t-test) were used for data analysis at the significant level of 0.05 . QQ plot diagrams were used to determine the normality distribution of the variables. It should be noted that all statistical calculations were performed by software AMOS20 and SPSS21. As shown in Table 1, all components of a personal brand image have a desired reliability.

Table 1. Reliability Statistics of Subscales

\begin{tabular}{lc}
\hline Sub-Scale & Cronbach's Alpha \\
\hline Fair behavior & 0.87 \\
Skill & 0.70 \\
Competition style & 0.74 \\
Success & 0.79 \\
Attractiveness & 0.75 \\
Life story & 0.80 \\
Reliability & 0.79 \\
Communication & 0.75 \\
Social responsibility & 0.69 \\
Psychological commitment & 0.81 \\
Loyalty & 0.73 \\
Total reliability & 0.77 \\
\hline
\end{tabular}

\section{RESULTS}

Descriptive Results. According to the results of Table 2, most of the sample group were 18-26 years old, single, female, with a bachelor's degree, with more than 9 years of sports experience, a championship experience, Asian championship experience, no experience of Brand support was specific without the use of marketing and branding consultants and experts. As shown in Figure 1, given the straight-line data, it can be assumed that the data of the personal brand image components have a normal distribution.

Inferential Findings. In this section, using structural equation modeling, the research parameters will be analyzed and estimated and the research hypotheses will be tested. Figures 2 and 3 represent the path coefficient diagram and $t-$ statistic values of the structural equation model to explain the research hypotheses, respectively. The results of the path analysis of the components of personal brand image are summarized in Table 3. As shown in the factor analysis model, the factors of competition style and skill have the most factor loadings. 
As shown in the Table 3, the story of life has been excluded from the model because of low coefficients. The model fit Table is shown below.

The results of Spearman test in Table 4 showed a significant relationship between demographic information and dimensions of personal brand image in national male and female taekwondo players of the Islamic Republic of Iran and no significant relationship was found only between age and personal brand image of national male and female taekwondo players of the Islamic Republic of Iran. According to the results of Table 5, the components of a personal brand are desirable in taekwondo elite players.

Table 2. Frequency distribution and percentage of athletes based on demographic information

\begin{tabular}{|c|c|c|}
\hline Feature & $\mathbf{F}$ & $\%$ \\
\hline \multicolumn{3}{|l|}{ Age } \\
\hline $18-26 y$ & 21 & 84 \\
\hline $27-34 y$ & 4 & 16 \\
\hline \multicolumn{3}{|l|}{ Marital status } \\
\hline Married & 5 & 20 \\
\hline Single & 20 & 80 \\
\hline \multicolumn{3}{|l|}{ Level of study } \\
\hline Diploma & 4 & 16 \\
\hline Associate degree & 7 & 28 \\
\hline B.A & 14 & 56 \\
\hline \multicolumn{3}{|l|}{ Professional sports experience } \\
\hline $1-9 y$ & 12 & 48 \\
\hline Over $9 \mathrm{y}$ & 13 & 52 \\
\hline \multicolumn{3}{|c|}{ Asian and world championship experience } \\
\hline With champion history & 19 & 76 \\
\hline With no champion history & 6 & 24 \\
\hline \multicolumn{3}{|l|}{ Supporting a particular brand } \\
\hline Support for a specific brand & 3 & 12 \\
\hline No experience in this regard & 22 & 88 \\
\hline \multicolumn{3}{|c|}{ Take advantage of the advice of marketing and branding specialists } \\
\hline Non-use & 23 & 92 \\
\hline Hiring branding specialist & 2 & 8 \\
\hline
\end{tabular}

\section{Normal Q-Q Plot of tasvirebrand}

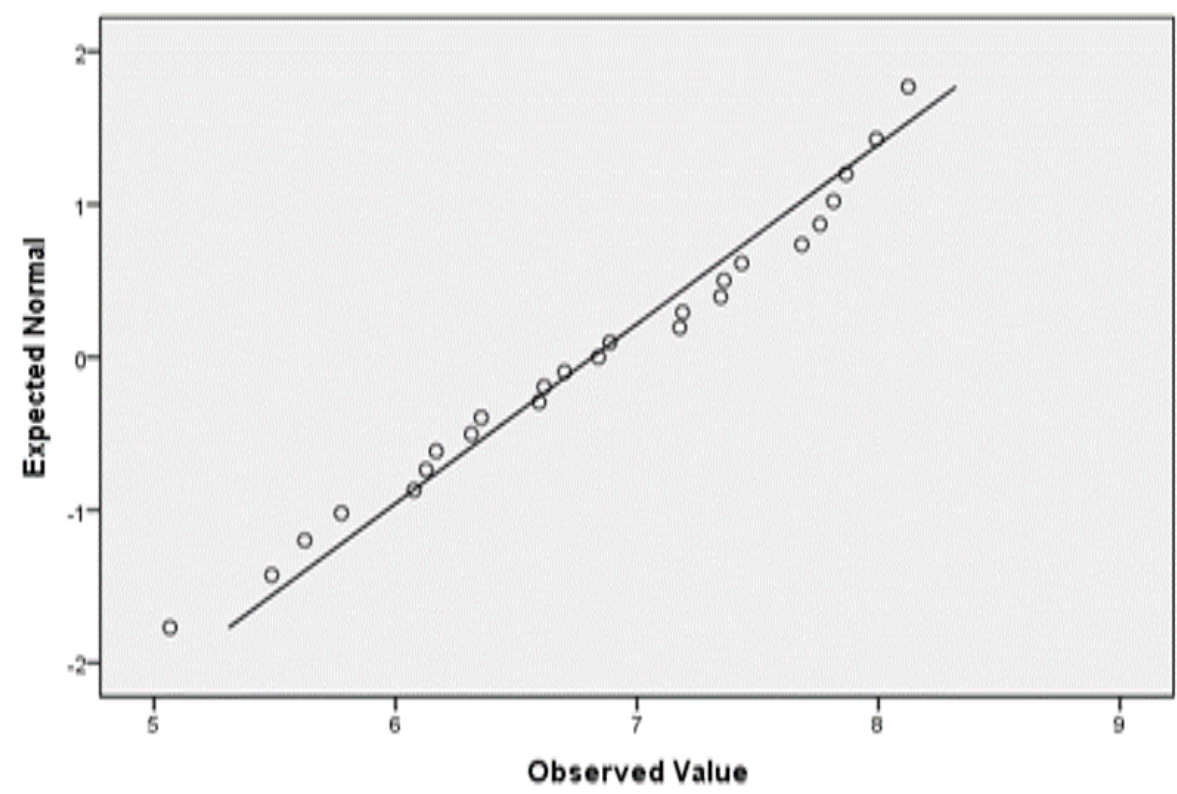

Figure 1. Normal Distribution State of Variables 


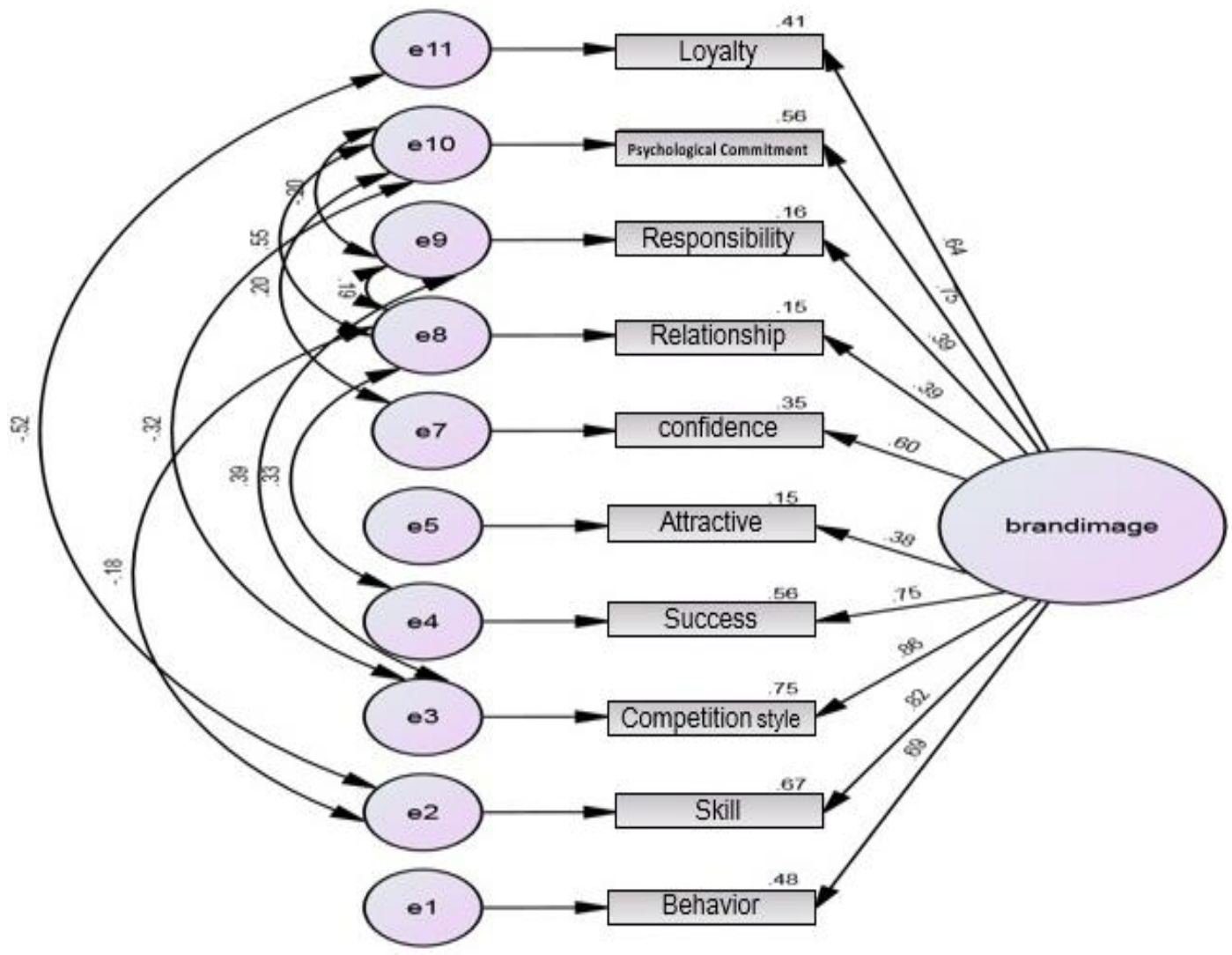

Figure 2. Factor Structural Model

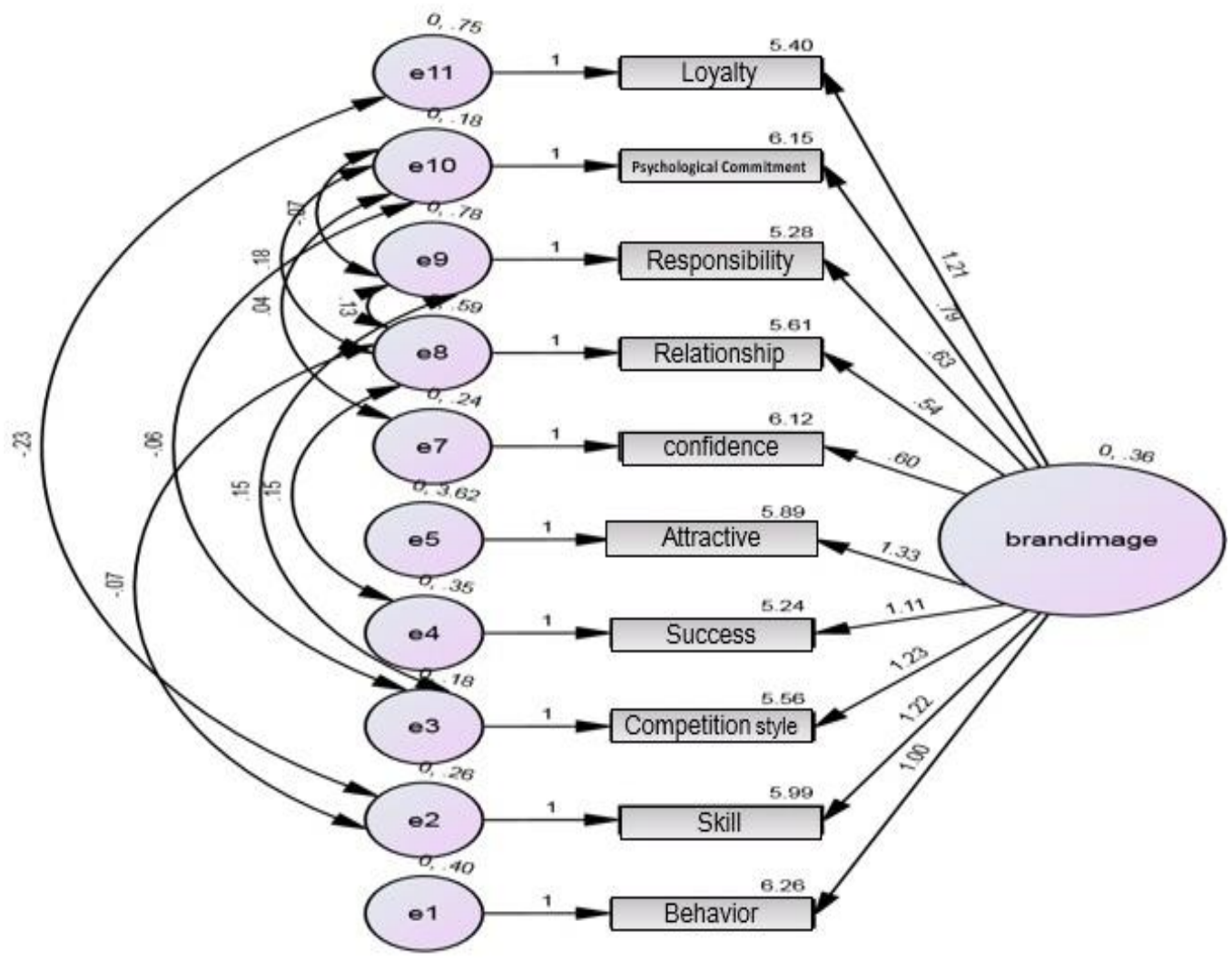

Figure 3. Non-Standard State Factor Structure Model 
Table 3. Path Analysis of Components of Personal Brand Image

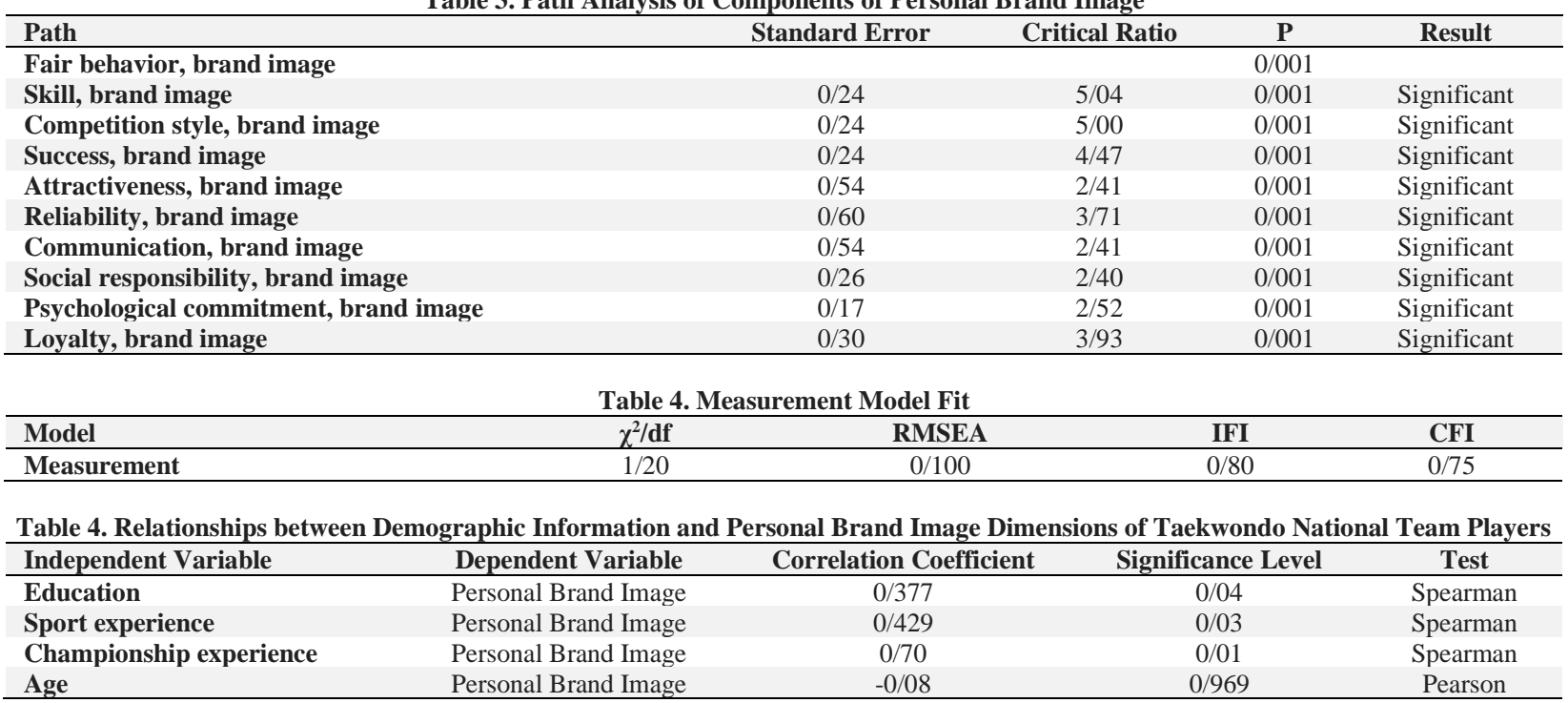

Table 5. Description of the Dimensions of Personal Brand Image among Male and Female Taekwondo Players

\begin{tabular}{lcccc}
\hline Component & T & Significance Level & M & State of Variable \\
\hline Fair behavior & $-1 / 17$ & $0 / 03$ & $6 / 31$ & Desired \\
Skill & $-0 / 76$ & $0 / 01$ & $6 / 11$ & Desired \\
Competition style & $-0 / 44$ & $0 / 04$ & $5 / 75$ & Desired \\
Success & $0 / 50$ & $0 / 01$ & $5 / 80$ & Desired \\
Attractiveness & $-0 / 71$ & $0 / 04$ & $5 / 77$ & Desired \\
Life story & $-4 / 91$ & $0 / 04$ & $5 / 16$ & Desired \\
Reliability & $-1 / 24$ & $0 / 03$ & $6 / 14$ & Desired \\
Communication & $-1 / 60$ & $0 / 02$ & $5 / 35$ & Desired \\
Social responsibility & $-2 / 11$ & $0 / 01$ & $5 / 64$ & Desired \\
Psychological commitment & $1 / 21$ & $0 / 01$ & $6 / 38$ & Desired \\
Loyalty & $-1 / 53$ & $0 / 04$ & $5 / 71$ & Desired \\
Brand image & $10 / 64$ & $0 / 001$ & $6 / 81$ & Desired \\
\hline
\end{tabular}

\section{DISCUSSION}

In recent years, with understanding the importance of branding for various industries, sports industry has also adopted the use of branding techniques, as well as other industries, to achieve its goals. One of these techniques is personal branding for athletes. The present study was conducted aimed to investigate and compare the brand image of Taekwondo elite players in Iran. The results of the research model showed that the component of fair behavior is one of the factors influencing personal brand image. Saffar et al. (2016) also identified fair behavior as a factor in enhancing athletes' personal brand image (17). The fair behavior, referring to factors related to humanity in the field of sports, plays a decisive role in building an ideal personal brand image. The fair competition with rivals, controlling the inner emotions on the field, and respecting competitors as well as fans are among the cases that create a good personal brand image in individuals' minds. In general, the same perceptions of the concepts, the degree of equal importance among different social classes, as well as the same elements and constituents of the fair behavior in the international fields are all important reasons for this finding. Of course, the fair behavior in physical and behavioral sports based on hitting an opponent also contributes to improving the image of athletes. Because an athlete who knows the basics of chivalry while fighting his opponent provides a much better image. According to the results, the skill component has a significant positive effect on the personal brand image of Taekwondo elite players. This finding is consistent with the study results of Tajnesai et al. (2014), Saffar et al. (2016), Sassenberg et al. (2012), Akiko and Yong (2013), and Andrew and Jackson (2013) (16, 17, 19, 20, 24). Andrew and Jackson (2013) stated that, in general, the image reflected by players is largely based on their individual skill, agility and creativity (16). Skill is an ability created by exercise and experience that results in minimal energy and time. Having high athletic skills in one field, having high skill in sports, beautiful and high quality performance of skills and good and reliable performance in sports competitions, and 
etc. are among the constructs of personal brand image related to the skill, which is evaluated as desired from Iranian Taekwondo national players' perspective Regarding the overwhelming audience interest in elite players' performance and its strong influence on enhancing personal brand development, it is suggested that Taekwondo elite players consider factors such as good and effective exercise, the use of skilled and capable coaches as well as the use of updated knowledge in Taekwondo first to promote their performance and skill, and second, enhance personal brand image.

Attractiveness obtained from attractive appearance, how to dress nicely, beautiful looks, and proper limbs are among the important things in creating a good image. Given the desired average of the subscales of attractiveness in the subjects, the same amount of attention paid is deduced to this important category in Taekwondo champions of the country. This section of the study results is consistent with the study results of Tajnesai et al. (2014), Hermansen (2010), Sassenberg et al. (2012) and Akiko and Yong (2013) $(19,20,24,25)$, Tajnesai et al. (2014) in their study found that apparent attractiveness had a positive effect on the promotion of athletes' personal brand image (24). The nice dress in the public fields, desired and appropriate treatment of the visual media, the use of proper lectures, and etc. are other important aspects of attractiveness. Then, according to the study results, communication, which in this study means communication skills, is introduced as another influential component of personal brand image. In their study, Lyle and Wetsch (2012) stated that in order to form and develop a personal brand, one should also develop one's personal skills in the application of communication technologies so that by establishing a strong communication in the communication networks through the media and Internet one can professionally try for personal brand development (26). Johnson (2017) also in his study showed that using social media such as Instagram, YouTube, Linkedin, websites and blogs can be effective on transferring students' personal brand (22). Communication is defined as the ability by which one can communicate more effectively and efficiently with one's surroundings. The successful social interactions are undoubtedly rooted in the use of proper communication skills. Undoubtedly, the use of communication skills in sports fields will enhance the athletes' personal brand image. Respecting fans and spectators, appreciating fans, sustained engagement with social media, and presence on social media for two-way communication with fans are among the cases that will enhance personal brand image in athletes and champions.

According to the results, social responsibility is another factor influencing Taekwondo's personal brand image. Saemian et al. (2013), Sassenberg et al. (2012), and Akiko and Yong (2013) have also noted this in their studies $(2,19$, 20). Responsibility is a personality trait that is usually formed as an attitude in one's mental and behavioral structure and is a major and fundamental variable in social behaviors and therefore has an interesting place in the teaching of social behaviors. Responsibility in the individual and social dimensions is a concept that can be a good tool and mean for maintaining social integrity while respecting and understanding existing differences. It should be noted that participating in charity plans, helping individuals, doing charitable activities, attending public events, and etc. are among the social responsibilities that will enhance a positive brand image of athletes and champions. Finally, according to the study results, psychological commitment is another effective factors. These results are consistent with the study results of Saeemian et al. (2013), Sassenberg et al. (2012) and Ahmad et al. (2016), and they have noted this in their studies $(2,19,27)$. Commitment and selfinterest, commitment to top teams and participation in large and international fields, as well as continued success, are some of the factors that drive psychological commitment in athletes. The more athletes have the better psychological commitment, the more brand image they have in their fans' minds.

Since the objectives of the present study were to determine the dimensions of personal brand and compare the personal brand image of athletes as well as determine the relationship between demographic information and personal brand image of elite male taekwondo players of the Islamic Republic of Iran, one can notice demographic information as effective on the development of athletes' personal brand. The demographic results showed that approximately $84 \%$ of subjects were under 26 years old. This indicates that Iran's Taekwondo champions and elites are part of the country's young 
professional sports community. The knowledge of personal brand image and planning to promote it can add to their retention in sports and even non-sports fields during retirement. According to the study results, it was found that nearly $56 \%$ of the subjects had a bachelor's degree. Considering the positive and significant relationship between education and personal brand image of athletes, it can be concluded that the higher the education of individuals, the higher the level of awareness of the components of personal brand and thus the athlete recognizes the strengths and weaknesses and will have a better personal brand image in individuals' minds. In addition to the study results and the positive and significant relationship between personal brand image and sporting experience, it can be stated that athletes with experiences of attending different fields and competitions in different settings over time obtained experiences of different contexts. These include experiences of media and fans, competition and success, increased professional and psychological skills, and etc. Accordingly, it can be said that increasing the experience of professional athletes will enhance their personal brand. Regarding Taekwondo young elite players of the Islamic Republic of Iran, it can be said that with increasing age and experience they should have a more desired personal brand image in the future. According to the study results, $76 \%$ of athletes also had an experience of championship and nearly the same percentage of individuals with championship levels were higher than Asian champion. Championship at different levels will increase the validity among the individuals and the media. Accordingly, more attention and planning is needed to raise awareness of the factors that make up a personal brand. This section of the results of demographic information is consistent with the study results of Hermansen (2010) and Sassenberg et al. (2012). According to the above, a significant and direct relationship was found between personal brand image and championship experience of taekwondo professional players $(19,25)$.

\section{CONCLUSION}

According to the results of demographic information, approximately $88 \%$ of athletes did not experience the support for a sports or nonsports brand. One of the reasons for this is the low age and experience of low attendance on the global fields. Undoubtedly, confirmation or support for a sports trademark and brand will have a great effect on enhancing the brand image in the public view. It is the task of Taekwondo Federation of the Islamic Republic of Iran to inform, provide, and facilitate the accomplishment of this important task for athletes. At the macro level, however, one of the reasons for the lack of support for sports or nonsports brands by athletes can be the inadequate coverage of taekwondo events in the national media. Finally, according to the results of demographic information, nearly 92 percent of the country's taekwondo national players also lack the advice of a marketing and branding specialist. Undoubtedly, the presence of a specialist alongside the athletic champions will not only enhance their personal brand, but will also increase the amount of income gained from professional sports and increase the validity of international sports fields. The reflection of this fundamental weakness and other such cases of the national champions of the country can be attributed to sports management and marketing researchers in papers like the present paper.

\section{APPLICABLE REMARKS}

- What distinguishes an athlete from other individuals is the effect on the external image, so athletes need to know their features and distinctions and have a plan to enhance and develop their own brand.

- Undoubtedly, highlighting the advantages to others is one of the success factors in personal branding.

- Careful consideration and understanding of moral and skill purchases and consulting with a sports marketing and branding specialists are among the suggestions that are offered to Taekwondo national players to form and develop a personalized brand image.

\section{REFRENCES}

1. Saemian S, Mohammadian M, Mir Moeini H, Shahrokhi F. Investigating the Impact of Cultural Components on Individual Brand Model Based on Individual Competencies. cult manage . 2013;7(4):7186. 
2. Mourad M, Ennew C, Kortam W. Brand equity in higher education. Mark intell Plann. 2011;29(4):403420. doi: $10.1108 / 02634501111138563$

3. Arai A, Ko YJ, Ross S. Branding athletes: Exploration and conceptualization of athlete brand image. Sport Manage Rev. 2014;17(2):97-106. doi: 10.1016/j.smr.2013.04.003

4. Schawbel D. Me 2.0: 4 steps to building your future: Kaplan Publishing; 2010.

5. Tabatabaeian F, Khabiri M, Rasooli M. Brand Personality of the Premier League of Iran's Soccer Strategies and Consequences. Ann Appl Sport Sci. 2018;6(2):87-94. doi: 10.29252/aassjournal.6.2.87

6. Cortsen K. Annika Sörenstam - a hybrid personal sports brand. Sport Bus Manage Int J. 2013;3(1):3762. doi: 10.1108/20426781311316898

7. Rampersad HK. A new blueprint for powerful and authentic personal branding. Perform Improv. 2008;47(6):34-37. doi: 10.1002/pfi.20007

8. Deheshti M, Adabi Firouzjah J, Alimohammadi H. The Relationship between Brand Image and Brand Trust in Sporting Goods Consumers. Ann Appl Sport Sci. 2016;4(3):27-34. doi: 10.18869/acadpub.aassjournal.4.3.27

9. Aaker DA. Measuring Brand Equity Across Products and Markets. California Manage Rev. 1996;38(3):102-120. doi: 10.2307/41165845

10. Roy D, Banerjee S. CARE-ing strategy for integration of brand identity with brand image. Int J Commerc Manage. 2008;17(1/2):140-148. doi: 10.1108/10569210710776512

11. Martenson R, Dennis C. Corporate brand image, satisfaction and store loyalty. Int J Retail Distrib Manage. 2007;35(7):544-555. doi: 10.1108/09590550710755921

12. Abdavi F, Shiralizadeh Z. The Effect of Brand Extension Strategy on Its Image: The Case of Majid Brand. Ann Appl Sport Sci. 2015;3(4):39-48. doi: 10.18869/acadpub.aassjournal.3.4.39

13. Villarejo-Ramos AF, Sánchez-Franco MJ. The impact of marketing communication and price promotion on brand equity. J Brand Manage. 2005;12(6):431-444. doi: 10.1057/palgrave.bm.2540238

14.Zarei Mahmoudabadi M, Keshtidar M, Razavi SMJ. The Impact of Sport Financial Sponsorship on Brand Equity and Performance: Structural Equation Modeling (SEM) Approach. Ann Appl Sport Sci. 2019;7(3):0-0. doi: 10.29252/aassjournal.712

15. Saunders K. A Case Study of Four Entrepreneurs on Their Quest to Achieve Professional Success in the Age of the Personal Brand (Doctoral dissertation, University of North Carolina at Wilmington). Wilmington: University of North Carolina Wilmington; 2012.

16. Arai A, Ko YJ, Kaplanidou K. Athlete brand image: scale development and model test. Eur Sport Manage Q. 2013;13(4):383-403. doi: 10.1080/16184742.2013.811609

17. Gilchrist P. Local heroes and global stars: Routledge; 2004.

18. Carlson BD, Donavan DT. Concerning the effect of athlete endorsements on brand and team-related intentions. Sport Mark Q. 2008;17(3):154-162.

19. Moshabbeki Esfahani A, Vahdati H, Khodadad Hosseini SH, Ehsani M. Designing The Brand Identity Model of Iranian Sports Industry (Case Study: Football Premier League). Manage Res Iran. 2014;17(4):203-223.

20. Taj Nesaie H, Taleban Z, Dehghan Chachkami M, editors. Athletes' branding: Identifying and reviewing the brand image of athletes from the perspective of fans (Case Study: Ali Daei Brand). National Conference on Marketing Research; 2014: Journal of Research in New Marketing Research.

21. Saffar Y, Azimzadeh M, Kafashpour A. Analysis of effective factors in the formation of brand image of professional athletes. q manage dev sport. 2015;1(8):85-103.

22.Hermansen AM. The athlete brand. Copenhagen: behind the science.

23. Morgan M. Personal branding: Create your value proposition. Strateg Finance. 2011;93(2):13.

24. Wetsch LR. A personal branding assignment using social media. J advert Educ. 2012;16(1):30-36.

25.Kucharska W, Thomas J. Personal Branding and Brand Loyalty, Social Network Users Brand Identification: Polish-French Model. SSRN Electron J. 2017. doi: 10.2139/ssrn.2990354

26. Nolan L. The impact of executive personal branding on non-profit perception and communications. Publ Relat Rev. 2015;41(2):288-292. doi: 10.1016/j.pubrev.2014.11.001

27. Ahmad R, Hashim L, Harun N. Criteria for Effective Authentic Personal Branding for Academic Librarians in Universiti Sains Malaysia Libraries. Soc Behav Sci. 2016;224:452-458. doi: 10.1016/j.sbspro.2016.05.420 